\title{
Naturaleza jurídica y efectos de las consultas públicas
}

\author{
Legal nature and effects of public consultations
}

\section{Natureza jurídica e efeitos das consultas públicas}

\author{
Gelacio Juan Ramón Gutiérrez Ocegueda ${ }^{l}$ \\ Universidad de Guadalajara, México \\ juan_r_gtz@yahoo.com \\ https://orcid.org/0000-0001-8880-094X
}

\section{Resumen}

En este trabajo se refieren las bases fundamentales de los derechos humanos, así como el sustento de la democracia y de las consultas públicas en el contexto mexicano para abordar los marcos teóricos y conceptuales concernientes a tópicos propios de los derechos humanos, democracia y consultas públicas. El objetivo fue para transitar hacia el estudio particular de la regulación normativa de las consultas públicas en el estado mexicano para afrontar ulteriormente un análisis comparativo que en el ámbito de las consultas públicas han experimentado diversos países. Para ello, se han aplicado los métodos sintético, analítico y dialéctico con el fin de determinar si las consultas públicas lograrán acercar el derecho humano de la democracia a toda la sociedad. Como conclusión se puede indicar que el sistema jurídico mexicano no cuenta con una adecuada regulación normativa para dichas consultas, por lo que se puede afirmar que debido a un ínfimo grado de eficacia y eficiencia, no es factible garantizarles un alentador porvenir.

\footnotetext{
${ }^{1}$ Gelacio Juan Ramón Gutiérrez Ocegueda es abogado egresado de la Facultad de Derecho de la Universidad de Guadalajara, Jalisco, México; titular del Diplôme Supérieur de I'Université de Droit, d'Économie et Sciences Sociales de Paris II; y del Diplôme d'Études Doctorales de I'Université Panthéon-Assas Paris II; profesor investigador de tiempo completo titular C, de la Universidad de Guadalajara, Jalisco, México; perfil Prodep vigente, y miembro del Sistema Nacional de Investigadores del Consejo Nacional de Ciencia y Tecnología nivel I durante los periodos 2009-2011, y 2013-2015, abogado postulante para diversas instituciones del sector financiero mexicano.
} 


\title{
Revista Iberoamericana \\ de las Ciencias Sociales y \\ Humanísticas
}

ISSN: $2395-7972$

Palabras clave: democracia, derechos humanos, consultas públicas.

\begin{abstract}
In this work the fundamental bases of human rights are known, as well as the sustenance of democracy and public consultations in the Mexican context, thus addressing the theoretical and conceptual frameworks, concerning topics typical of human rights, democracy and public consultations, to move towards the particular study of the regulatory regulation of public consultations in the Mexican state, to further face a comparative analysis that various countries have experienced in the field of public consultations. It is developed with the support of synthetic, analytical and dialectical methods, to determine if it is through Public Consultations that the human right of democracy will be brought closer to the whole society, the result of which is that the Mexican legal system does not have an adequate regulatory regulation applicable to topics specific to these consultations, and confirming that before a very small degree of effectiveness and efficiency it is not feasible to guarantee them an encouraging future.
\end{abstract}

Keywords: democracy, human rights, public consultations.

\section{Resumo}

Este trabalho se refere às bases fundamentais dos direitos humanos, bem como à sustentação da democracia e das consultas públicas no contexto mexicano para abordar os marcos teóricos e conceituais relativos aos temas de direitos humanos, democracia e consultas públicas. O objetivo foi avançar para o estudo particular da regulamentação normativa das consultas públicas no Estado mexicano para, posteriormente, enfrentar uma análise comparativa que diversos países experimentaram no campo das consultas públicas. Para tanto, métodos sintéticos, analíticos e dialéticos têm sido aplicados para determinar se as consultas públicas aproximarão o direito humano à democracia de toda a sociedade. Em conclusão, pode-se assinalar que o ordenamento jurídico mexicano não possui regulamentação normativa adequada para tais consultas, de modo que se pode afirmar que, por um grau desprezível de eficácia e eficiência, não é viável garantir-lhes um futuro animador.

Palavras-chave: democracia, direitos humanos, consultas públicas. 
Revista Iberoamericana

de las Ciencias Sociales y

Humanísticas

Fecha Recepción: Junio 2020

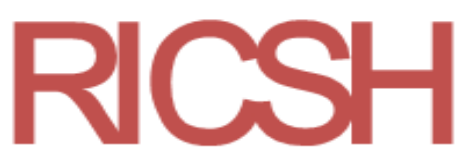

ISSN: 2395 - 7972

Fecha Aceptación: Diciembre 2020

\section{Introducción}

La democracia - sea entendida como concepto, forma de gobierno y mecanismo para establecer la relación entre gobernantes y gobernados - tiene un largo camino desde su nacimiento y evolución hasta su conceptualización actual. De hecho, este concepto no surge, por lo menos en principio, como una pretensión de derechos humanos, sino como una evolución de estos, lo que ha originado que se considere como un derecho humano moderno.

En el contexto social existe una infinidad de reglas de conducta, algunas de las cuales ni siquiera se encuentran escritas, pero regulan la vida de los individuos en sociedad para dotarla de cierta armonía, mientras que otras son puestas en vigor por el Estado para garantizar el cumplimiento de obligaciones y, por ende, el estado de derecho. Sin embargo, en los derechos humanos, y sobre todo en relación con la democracia, es un ámbito aún no explorado, el cual toma relevancia en la actualidad debido al surgimiento de las consultas públicas como una figura no legal en la que se pretende que el ciudadano haga prevalecer su derecho humano a libre ejercicio democrático, o por lo menos para que considere que se encuentra ante un gobierno democrático que solicita al gobernado su valiosa opinión.

Al respecto, Capellán de Miguel (2018), en su propuesta para repensar la historia conceptual de la democracia en el mundo iberoamericano y tomando en cuenta su peso específico desde una vertiente histórica y semántica, refiere lo siguiente:

La democracia se había convertido en ese largo tiempo de uso creciente en una especie de repositorio — en un “concepto contenedor”- donde se habían ido acumulando históricamente todos los conceptos y valores políticos positivos que una parte de la sociedad occidental había, primero aspirado y luego conquistado: libertad, derechos, igualdad, progreso, justicia (p. 146).

El nexo entre democracia y derechos humanos figura en el la Declaración Universal de Derechos Humanos, proclamada en París el 10 de diciembre de 1948 por la Asamblea General de las Naciones Unidas (ONU) (1948) mediante el pronunciamiento de la Resolución A (III), la cual establece: 


\section{Revista Iberoamericana \\ de las Ciencias Sociales y Humanísticas}

ISSN: $2395-7972$

La voluntad del pueblo es la base de la autoridad del poder público; esta voluntad se debe expresar mediante elecciones auténticas que habrán de celebrarse periódicamente, por sufragio universal e igual y por voto secreto $\mathrm{u}$ otro procedimiento equivalente que garantice la libertad del voto (artículo 21).

Respaldándose en la libertad de opinión, expresión y transparencia en la administración pública, en fechas recientes se ha utilizado de manera reiterada la figura de las consultas públicas por parte del Ejecutivo federal como una manera de aparentar la democracia y, sobre todo, legitimar sus decisiones. Sin embargo, esta figura de las consultas públicas no está debidamente reglamentada, ya que no se tienen establecidos los procedimientos, parámetros ni efectos de su realización y su resultado, ni queda claro si están o no establecidas legalmente.

Esta investigación, por tanto, encuentra su justificación en el uso excesivo del mecanismo de consulta pública, en su aplicación a tópicos impertinentes a este instrumento democrático y en su subutilización en aspectos relevantes de la vida nacional, lo que solo refleja la ausencia de valor y voluntad política para asumir los riesgos derivados de una directa pero desertada determinación gubernamental, o bien la carencia de la preparación suficiente para concretarlas.

\section{Objetivos e hipótesis}

La pretensión general del actual trabajo investigativo es analizar los fundamentos de los derechos humanos y sus distintas consideraciones, así como el concepto y evolución de la democracia para poder establecer si esta última se encuentra contemplada como contenido esencial de estos; en caso contrario, confirmar si su inclusión explícita es una necesidad en la realidad actual de México y si su omisión o ausencia tiene implicaciones negativas para el correcto y óptimo desarrollo y progreso de la vida social del país, pretendiendo determinar si es a través de las consultas públicas que se logrará acercar el derecho humano de la democracia a toda la sociedad.

Como objetivos particulares se precisan los siguientes: (i) identificar los antecedentes de los fundamentos de los derechos humanos, la democracia y las consultas públicas en México; (ii) analizar la naturaleza y características de los derechos humanos, su génesis y distintas generaciones; (iii) conocer la naturaleza de la democracia y sus principales 


\section{Revista Iberoamericana \\ de las Ciencias Sociales y Humanísticas}

ISSN: 2395 - 7972

conceptos, origen, evolución y justificación; (iv) conocer la naturaleza de las consultas públicas y sus principales conceptos, origen, evolución y justificación; (v) establecer si la democracia como ideología pertenece a los derechos humanos, su importancia y trascendencia social; (vi) determinar si actualmente las consultas públicas son un principio fundamental de todo lo concerniente a los derechos humanos en sus distintas manifestaciones; (vii) analizar las escuelas, teorías, corrientes del pensamiento e ideas que, como marco teórico, resulten aplicables a la prevención o resolución del problema objeto de estudio en la presente investigación; (viii) integrar el marco conceptual conveniente para el estudio de las instituciones que se evocan en este estudio investigativo; (ix) examinar las disposiciones normativas federales reguladoras de las figuras jurídicas que convergen recurrentemente en la actividad investigativa desarrollada en este trabajo de investigación documental; (x) realizar un análisis comparativo de las experiencias que en materia de consultas públicas han tenido otros países en vista a demostrar la hipótesis aquí formulada, y (xi) determinar si conforme al análisis efectuado de los antecedentes, marcos teórico, conceptual, normativo y las experiencias que en materia de consultas públicas han tenido otros países, el régimen mexicano permite que las consultas públicas se regulen y ejerzan con eficacia y eficiencia.

Como hipótesis se plantea que la democracia debe ser considerada como un principio elemental de los derechos humanos dentro de la estructura y sistema jurídico de nuestro país. Lo anterior en razón de que de este principio se derivan una serie de implicaciones de diversas índoles que afectan la esfera particular de las personas y se reflejan en su bienestar y pacífica convivencia. Las consultas públicas son una de las formas de acercar la democracia al colectivo social, siempre que estén debidamente regulados su naturaleza y sus procesos para obtener la legitimación de sus resultados.

\section{Materiales y métodos}

La presente investigación se encuentra desarrolla con apoyo de los métodos (i) sintético (que consiste en un proceso mediante el que se relacionan hechos aparentemente aislados y se formula una teoría que unifica los diversos elementos de los derechos humanos, la democracia y las consultas públicas); (ii) analítico (por el que se distinguen los elementos de fenómenos resultantes de dichos conceptos) y se procede a revisar ordenadamente cada uno de ellos por separado, (iii) y dialéctico (al considerar los fenómenos históricos y sociales 


\section{Revista Iberoamericana \\ de las Ciencias Sociales y Humanísticas}

ISSN: 2395 - 7972

inherentes a los derechos humanos, la democracia y las consultas públicas, toda vez que están en continuo movimiento, dado que la realidad no es algo inmutable, sino que está sujeta a contradicciones, así como a una evolución y desarrollo perpetuo, y proponer este método de todos los fenómenos para que sean estudiados en relación con otros, y en su estado de continuo cambio, en virtud de que dicho método considera que nada existe como un objeto aislado, sino que cada forma o fenómeno social, al tener sus características propias y peculiares, debe ser estudiado en su proceso de transformación interno.

Consecuentemente, se han tomado en consideración las orientaciones brindadas por diversos autores en materia metodológica, principalmente por la obra de Rojas (2012), la cual se enfoca en la investigación en ciencias sociales.

En cuanto a las técnicas de recopilación de datos empleadas para la elaboración de la presente investigación, se consultaron - entre otras - las bases Redalyc, Scielo, Scopus y Ebsco, donde se hallaron instrumentos de recopilación, clasificación, medición, correlación y análisis de datos.

El desarrollo de esta investigación se fundamentó esencialmente en la técnica documental de recopilación de datos, ya que debido a la naturaleza de la temática planteada, la búsqueda realizada fue eminentemente heurística, ya que se centró en el estudio de ciertos datos condicionantes del ejercicio de los derechos humanos, la democracia y las consultas públicas, por lo que de su examen y crítica se han planteado una serie de preguntas y se ha formulado la hipótesis sobre la que se centra esta investigación.

En virtud de lo anterior, la búsqueda documental de datos realizada en esta investigación presenta las fisonomías particulares siguientes: (i) se ha acudido preferentemente a fuentes primarias; (ii) se han utilizado los clásicos de la especialidad tanto antiguos como contemporáneos, por lo que el rango de consulta osciló entre 1960 y 2019; (iii) no solo se ha recopilado y acumulado información, sino que además se ha valorado, analizado y efectuado aportaciones personales; (iv) no se ha medido la calidad de la investigación en función de su cantidad, sino por su contenido e idoneidad, y (v) la información se ha referido al problema identificado, la cual se ha seleccionado, analizado y valorado sistemáticamente. 
Revista Iberoamericana

de las Ciencias Sociales y

Humanísticas

ISSN: 2395 - 7972

\section{Resultados}

Los resultados se muestran a través del abordaje de los tres apartados siguientes: 1) marcos teóricos y conceptual inherentes a derechos humanos, democracia y consultas públicas; 2) bases de los derechos humanos, de la democracia y de las consultas públicas en México, y 3) regulación normativa de las consultas públicas en México.

\section{Bases de los derechos humanos, de la democracia y de las consultas públicas en México \\ Derechos humanos}

Al efecto, se realizó una compilación enunciativa y parafraseando a Nogueira (2003), respecto a los soportes de los derechos humanos a través de la historia: (i) fundamentación iusnaturalista u objetivismo jurídico, que comprende a su vez la corriente del derecho natural ontológico sustentada en las concepciones tomistas y neotomistas; la corriente del iusnaturalismo racionalista y las teorías del contrato social que implican al contractualismo clásico y al neocontractualismo, y el iusnaturalismo deontológico contemporáneo o fundamentación ética o axiológica de los derechos humanos; (ii) fundamentación de forma y de contenido y estructura, enfrentando por la primera el requerimiento de transformar el contenido dogmático de los derechos humanos en derecho positivo materializado, lo que se requiere para su conocimiento, su ejecución y su organización, y mediante la segunda el sustento de los derechos humanos tiene una bases en las ideas constructivas de los derechos fundamentales de Alexy (2012), donde los derechos humanos descansan sobre la base de la teoría del discurso y, por ende, sobre fundamentos teorético-discursivos directos de los derechos humanos, como son el argumento de autonomía ${ }^{2}$, el de consenso y el de la democracia, los cuales se complementan y refuerzan recíprocamente; (iii) el argumento de la autonomía, a partir del cual cada quien goza del derecho individual de juzgar libremente lo que resulte más beneficioso y qué es aceptable para actuar consecuentemente; (iv) el argumento del consenso, ya que la legitimación del derecho se encuentra estrechamente

${ }^{2}$ Recomendable consultar en el ámbito de la autonomía y consecuente emancipación la obra de Veca, S. (1990). Cittadinanza. Riflessioni filosofiche sullídea di emancipazione (Prima edizione in "Idee" marzo 1990 ed.). Milano, Italia: Gigjacomo Feltrinelli editore Milano. 


\section{Revista Iberoamericana de las Ciencias Sociales y Humanísticas}

ISSN: $2395-7972$

vinculada a la aceptación universal tanto de consagrarlo como de preservarlo; (v) el argumento de la democracia, ya que solamente a través de ella resulta posible que los derechos políticos fundamentales y los derechos humanos rijan y puedan ejercitarse con suficiente igualdad de oportunidades; (vi) la fundamentación historicista de los derechos humanos por la que se afirma que el fundamento de los derechos humanos se encuentra realmente en las necesidades sociales y la factibilidad de solventarlas en la sociedad; (vii) la fundamentación positivista por virtud de la cual el derecho es tal si se prevé en una norma positiva vigente y tendrá justificación propia e independiente a posibles justificaciones morales o sustento en valores; y (viii) la fundamentación trialista de los derechos humanos por virtud de la cual la existencia de un fenómeno jurídico implicará necesariamente la presencia tres elementos: un hecho subyacente, un valor que atribuye determinada situación a tal hecho y una normativa con función integradora de los elementos.

Mediante su postura de normativismo realista y crítico, Ferrajoli (2004) sustenta a todos aquellos derechos subjetivos que son reconocidos como inmanentes a todos los seres humanos provistos de la calidad de personas, ciudadanos o capaces de actuar, ya que por derecho subjetivo deberá entenderse lo siguiente:

Cualquier expectativa positiva (de prestaciones) o negativa (de no sufrir lesiones), adscrita a un sujeto por una norma jurídica, y por estatus, la condición de un sujeto, prevista por una norma jurídica positiva, como presupuesto de su idoneidad para ser titular de situaciones jurídicas y/o autor de los actos que son ejercicio de estas (p. 37).

Al respecto, advierte Nogueira (2003) de la existencia de diversas maneras de clasificar los derechos, entre las que se encuentran las siguientes: (i) según su objeto y finalidad; (ii) según el criterio del bien jurídico protegido y su finalidad; (iii) según el criterio de la forma de ejercicio de ellos; (iv) de acuerdo al criterio del tipo de relación jurídica que suponen; (v) según las diferencias de estatus de las personas; (vi) según su estructura; (vii) según los valores protegidos en ellos, y (viii) según los pactos internacionales.

Por consiguiente, es a partir de la clasificación en función del objeto y finalidad de los derechos humanos que aparecen los derechos políticos, que comprenden el derecho de participación en las consultas públicas.

En cuanto a la democracia, el primer vestigio de un régimen democrático en nuestro país lo encontramos en el artículo 4 de la Constitución del 4 de octubre de 1824 al admitir 


\section{Revista Iberoamericana \\ de las Ciencias Sociales y Humanísticas}

ISSN: $2395-7972$

como forma de gobierno una república representativa, popular y federal. Ulteriormente, es en el artículo 40 de la Constitución Política de los Estados Unidos Mexicanos que confirmamos tal circunstancia.

Hablemos ahora de la democracia como valor. En la Guía para Educadores Pares que como proyecto ha sido elaborado como acción para fortalecer el buen gobierno y rendición de cuentas en Uganda por la Oficina de Konrad- Adenauer-Stiftung (KAS) en dicho país (2011), y apoyado por la Unión Europea, encontramos que a la democracia se le atribuye el rango de valor:

Values are things people cherish and will protect to ensure their survival. Culture, which by simple definition is the way of life of a given people, is a good example of an embodiment of values. Democracy as a value, then, means that people will do anything to protect it as it is a part of their culture, thus a way of life of a given people

[Los valores son cosas que las personas aprecian y protegerán para garantizar su supervivencia. La cultura, que por definición simple es la forma de vida de un pueblo determinado, es un buen ejemplo de una encarnación de valores. La democracia como valor, entonces, significa que las personas harán cualquier cosa para protegerla, ya que es parte de su cultura, por lo tanto, una forma de vida de un pueblo determinado] (pp. 10-11).

Lo anterior sin menospreciar los valores de la democracia moderna que, como método de conformación de gobiernos y habilitación de políticas, implican la adopción de una serie de principios que la justifican y convierten en codiciable (al menos con respecto a otras modalidades de carácter principalmente autoritario) y que son producto de la evolución social fundados en la racionalidad de los pueblos: nos referimos a la libertad, a la igualdad y a la fraternidad.

A continuación, constatemos las modalidades en que se materializa la democracia ${ }^{3}$. La democracia directa se refiere a una forma de gobierno en la cual "el pueblo participa de manera continua en el ejercicio directo del poder", es una democracia autogobernante, pues el pueblo, reunido en asamblea, delibera y decide en torno a los asuntos públicos, actualmente

${ }^{3}$ Para profundizar sobre la evolución de la participación democrática y sus modalidades se sugiere

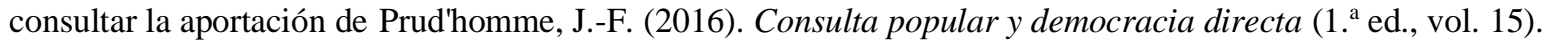
(I. N. Electoral, Ed.) Ciudad de México, México: Instituto Nacional Electoral. 


\section{Revista Iberoamericana \\ de las Ciencias Sociales y Humanísticas}

ISSN: $2395-7972$

se sigue practicando en pequeñas comunidades, como en los cantones de Glaris, Appenzell y Unterwald en Suiza. La democracia representativa es considerada una democracia indirecta, en la que el pueblo no gobierna, pero elige a representantes que lo gobiernan; en ella la toma de decisiones cuenta con suficiente información en la medida en que se desarrolla a través de diversas etapas y de una serie de filtros. Así, las limitaciones a la participación, asociadas al tamaño y a la complejidad de las sociedades, pueden ser superadas, la representación permite una política positiva que evita la polarización en la sociedad. Así, las minorías tienen voz y sus derechos están mejor protegidos.

Es cierto que en el momento de legislar o de participar en la toma de decisiones públicas el representante no siempre sirve de manera pura a los intereses de sus representados. Sus lealtades están divididas entre estos, su partido político y sus valores e ideales personales; por ello, en la actualidad son esas instituciones representativas las que constituyen el marco de la vida democrática. Los mecanismos de la democracia directa tales como el plebiscito, la iniciativa popular o la revocación de representantes - tienen que ser estudiados, pues actualmente deben de analizarse ambos tipos de democracia ${ }^{4}$.

Identifiquemos ahora las ventajas del gobierno representativo: (i) la protección otorgada a las minorías; (ii) la limitación a la demagogia y a los abusos del poder político; (iii) la estabilidad en las decisiones públicas; (iv) el cambio ordenado en las políticas y en el funcionariado político, y (v) el equilibrio entre la participación y la gobernabilidad.

Por su parte, las ventajas de la democracia directa son estas: (i) expresar de manera pura los intereses individuales; (ii) permitir la manifestación directa de la opinión pública en los procesos legislativos; (iii) incrementar la sensibilidad de los legisladores a los movimientos de opinión; (iv) reducir los efectos de distorsión creados por los partidos políticos y las asociaciones intermedias, y (v) incrementar la participación ciudadana.

En cuanto a la crisis democrática se refiere, es imperante tomar en consideración las particularidades de los sistemas políticos, así como las situaciones concretas en las cuales se aplican los métodos de consulta directa.

Una temática inevitable es la relativa a la crisis democrática. En ese sentido, vale la pena mencionar la postura de Fernández (2013), quien en su obra concerniente a la democracia como forma de gobierno se refiere a las estrategias gubernamentales dentro de

\footnotetext{
${ }^{4}$ La diversidad de variables democráticas es ampliamente explicada por Rodríguez Burgos, K. (2015). Democracia y tipos de democracia. Ciencia política. Perspectiva multidisciplinaria, 250.
} 


\section{Revista Iberoamericana}

de las Ciencias Sociales y

Humanísticas

ISSN: $2395-7972$

la democracia y a las crisis de los grandes modelos. Este autor sintetiza su impresión ante los diversos regímenes más económicos que políticos abarcando los de corte comunista, socialdemócrata, republicano, socialista, así como del estado del bienestar.

Resultado de los estudios efectuados revelan que "turning out to vote is the most emblematic means of participating in the democratic process. Low turnout rates are often interpreted as a signal of dissatisfaction with the political decision-making process" [El hecho de votar es el medio más emblemático para participar en el proceso democrático. Las bajas tasas de participación a menudo se interpretan como una señal de insatisfacción con el proceso de toma de decisiones políticas] (International Institute for Democracy and Electoral Assistance [IDEA], 2017, p. 105).

Nos encontramos, entonces, frente al valor de la libertad democrática que implica la capacidad de autogobernarse o autodeterminarse, característica indispensable de todo ciudadano políticamente activo y sustento del principio democrático fundamental de la soberanía popular.

Al referirse particularmente a la construcción de paz, inclusive en estados afectados por conflictos, y en la labor de diseño para la resiliencia de la democracia, el International Institute for Democracy and Electoral Assistance (2017) testifica que "inclusion does more than bring diverse groups into decision-making processes. It can also help promote broadmindedness in society and increase social tolerance. Inclusive, consensual systems promote mutual respect and tolerance, and help facilitate deliberation" [La inclusión hace más que traer diversos grupos a los procesos de toma de decisiones. También puede ayudar a promover la mentalidad abierta en la sociedad y aumentar la tolerancia social. Los sistemas inclusivos y consensuales promueven el respeto mutuo y la tolerancia, y ayudan a facilitar la deliberación] (p. 257).

Así, la cohabitación de las ideas debe favorecer la legitimidad y acción del poder público, por lo que toda democracia liberal debe contar con un mecanismo institucional de fijación de objetivos políticos que impida su sujeción a valores propios de una comunidad específica de personas. 


\section{Consultas públicas}

En lo concerniente a los antecedentes de esta figura en el sistema mexicano, el primero lo encontramos en la Ley de Participación Ciudadana del Distrito Federal. Sobre este precedente, constata Escobar (2014) que es la Ley de Participación Ciudadana del Distrito Federal el precursor inmediato de la consulta popular en México, bajo la connotación de consulta vecinal que, sujeta a un procedimiento sencillo, pretendía ser un instrumento de solución de problemáticas del lugar en que radicaban los ciudadanos o bien como instancia para plantear las necesidades e intereses de los residentes de un mismo sitio. Lo anterior en el entendido de que dicho ordenamiento fue abrogado en el año 2019 por la Ley de Participación Ciudadana de la Ciudad de México.

El segundo vestigio aparece en el artículo 35, fracción VII, y 36, fracción III, de la Constitución Política de los Estados Unidos Mexicanos. Efectivamente, esta institución se integra en el artículo 35, fracción VII y artículo 36, fracción III de la Carta Magna, al reconocer respectivamente como derechos del ciudadano votar en las consultas populares sobre temas de trascendencia nacional, y votar en las elecciones y en las consultas populares, en los términos que señale la ley.

El tercer precedente se localiza en la reforma constitucional del 10 de febrero de 2014, de la que emerge a la vida jurídica la Ley Federal de Consulta Popular, publicada en el Diario Oficial de la Federación el 14 de marzo de 2014, que funge como reglamentaria de la fracción VIII del artículo 35 de la Constitución Política de los Estados Unidos Mexicanos. Por tal motivo, Escobar (2014) señala que “con esta nueva regulación, se da un nuevo sentido a la Consulta Popular, pues se establecen los procedimientos mediante los cuales se puede poner en práctica este mecanismo de participación ciudadana” (p. 201).

Ahora bien, y en lo que se refiere al origen de las consultas públicas, para el desarrollo de este apartado aprovechamos la pertinencia de las palabras de Sartori (2009), quien asegura que las elecciones son libres únicamente si mediante ellas se expresan opiniones propias ${ }^{5}$ :

Se dice que las elecciones deben ser libres. Sin duda, pero también las opiniones deben ser libres, es decir, libremente formadas. Si las opiniones se imponen, las elecciones no pueden ser libres. Un pueblo soberano que no tiene

${ }^{5}$ De igual manera, se sugiere la lectura de la obra de este autor que se ha tornado indispensable para los estudiosos de esta temática: Sartori, G. (2007). ¿Qué es la democracia? (1. a ed.). Madrid, España: Taurus. 


\section{Revista Iberoamericana}

de las Ciencias Sociales y

Humanísticas

ISSN: $2395-7972$

nada que decir de sí mismo, un pueblo sin opiniones propias, cuenta menos que el dos de copas (p. 31).

Por otra parte, y reflexionando sobre lo que debe entenderse por opinión pública (cuya cristalización se realizaría hoy en día a través de las consultas públicas), y los efectos que aquella produce, Sartori (2009) aduce:

Que quede claro, una opinión difundida entre el gran público puede darse, y de hecho se da, sobre cualquier asunto. Por ejemplo, las opiniones sobre el futbol, sobre lo bello, sobre lo bueno, son también opiniones públicas, pero cuando se dice opinión pública a secas hay que entender que tiene como objeto la res publica, el interés colectivo, el bien público (pp. 31-35).

Se trata, entonces, de una especie de elocución emitida como opinión — no como voluntad - por un segmento de personas que expresan su sentir en asuntos públicos, por lo que dicho ejercicio conjuga tanto al sujeto como al objeto de la expresión, y que al ser representativo del interés general, bienestar general, interés público o del bien común, se refiere a algo inmanente la cosa pública.

Sobre las consecuencias de la expresión de la opinión pública se puede advertir la existencia de una gran sutileza, dado que "sigue siendo cierto que, incluso cuando conseguimos una opinión pública relativamente autónoma, el resultado es frágil y relativamente incompleto" (Sartori, 2009, pp. 31-35).

Con ello, se muestra una frustrante realidad que difícilmente podría ocultarse, ya que “es cierto que el público, el público en general, nunca está muy informado, no sabe gran cosa de política, y no se interesa demasiado por ella" (Sartori, 2009, pp. 31-35).

A manera de concepto, Sartori (2009) razona con respecto de la participación:

"Participación" es tomar parte activa, voluntaria y personalmente. "Voluntariamente" es un detalle importante, porque, si se obliga a la gente a participar a la fuerza, eso es movilización desde arriba y no participación desde abajo. Insisto: participación es ponerse en marcha por uno mismo, no que otros te pongan en marcha ni que te movilicen desde arriba (p. 35).

Hablando sobre la justificación de las consultas públicas, y desde nuestra forma de ver las cosas, las consultas públicas surgen como una necesidad de legitimar la existencia de una auténtica democracia, razonamiento que se identifica con el de Sartori (2009) al 


\section{Revista Iberoamericana}

de las Ciencias Sociales y

Humanísticas

ISSN: $2395-7972$

atestiguar que "las democracias, en su gris funcionamiento cotidiano, a menudo merecen poco crédito" (p. 38).

Ante tal realidad, es dable concluir que "el verdadero peligro que amenaza a una democracia que oficialmente ya no tiene enemigos no está en la competencia de contraideales, está en reclamar una 'verdadera democracia' que trasciende y repudia la que hay" (Sartori, 2009, p. 38).

Si la auténtica y principal característica de la democracia consiste en la remoción pacífica de los gobernantes que incumplen su función, el proceso electoral se convierte en un mecanismo de control más que de elección, para garantizar el respeto de su propia esencia: la alternancia en el poder.

En la Guía para Educadores Pares que como proyecto ha sido elaborado como acción para fortalecer el buen gobierno y rendición de cuentas en Uganda por la Oficina de KonradAdenauer-Stiftung (2011), en dicho país, y apoyado por la Unión Europea, encontramos la justificación de las consultas como forma de participación al indicar lo siguiente:

Democratic participation can occur in two ways: First, people can participate through established structures of the adopted forms of democracy; and second, they can participate through civil associations. In democracies, the election of leaders must be free and fair. In some societies, a referendum is used to decide on major issues of the day. In this way citizens become part of decisionmaking and governance

[La participación democrática puede ocurrir de dos maneras: primero, las personas pueden participar a través de estructuras establecidas de las formas de democracia adoptadas; y segundo, pueden participar a través de asociaciones civiles. En las democracias, la elección de líderes debe ser libre y justa. En algunas sociedades, se utiliza un referéndum para decidir sobre los principales problemas del día. De esta forma, los ciudadanos se convierten en parte de la toma de decisiones y la gobernanza] (p. 15).

Así, los retos que debe superar la democracia, muy probablemente mediante algunos ajustes que legitimen la participación social a través de las encuestas públicas, son evidenciados, reconociendo así la existencia de una resiliencia de la democracia: 
Political parties must tackle four key challenges to survive in the changing political landscape: (a) deliver results to address multifaceted challenges such as global economic crises, international terrorism and refugee flows; (b) restore citizens' sense of inclusion, particularly among marginalized groups; (c) respond to populism; and (d) adapt to new ways of interacting with both party members and the electorate.

These challenges relate to the resilience of democracy"

[Los partidos políticos deben abordar cuatro desafíos clave para sobrevivir en el cambiante panorama político: (a) entregar resultados para abordar desafíos multifacéticos como las crisis económicas mundiales, el terrorismo internacional y los flujos de refugiados; (b) restaurar el sentido de inclusión de los ciudadanos, particularmente entre los grupos marginados; (c) responder al populismo; y (d) adaptarse a nuevas formas de interactuar con los miembros del partido y el electorado.

Estos desafíos se relacionan con la resiliencia de la democracia] (IDEA, 2017, p. 98).

El término mismo de resiliencia democrática se concibe como aquella destreza gubernamental para afrontar inconvenientes del exterior sin comprometer la confianza en las instituciones propias ni la insatisfacción con respecto de la democracia.

Oportuna me parece — para los efectos de este trabajo investigativo - la opinión de Bovero (2012), quien la externa formulando una severa crítica a la forma en que se han venido adoptando las decisiones electorales, pues afirma que se ha transitado de una democracia hacia una pleonocracia:

En mi lenguaje, las elecciones ya no son democráticas, sino pleonocráticas, instituyen una suerte de tiranía electiva de la mayoría. Todo el poder a una parte del pueblo no es un principio democrático. En una democracia - de acuerdo a mi concepción de la misma - la función de las elecciones no es la de otorgarles directamente el poder de decisión colectiva a (los representantes de) una parte de los ciudadanos; sino la de determinar la composición del órgano autorizado a tomar las decisiones colectivas de manera que todas las opiniones de los ciudadanos encuentren representación política, sin excluir ninguna y en sus respectivas proporciones (p. 326). 


\section{Revista Iberoamericana \\ de las Ciencias Sociales y Humanísticas}

ISSN: $2395-7972$

Es consciente Bovero (2012) de la orientación a confluir en una variante que ha denominado autocracia electiva:

Las democracias reales contemporáneas en su conjunto evidencian una clara tendencia a converger hacia el segundo tipo de régimen, esto es, a realizar el segundo elemento de mi hipótesis abstracta. Se trata de un régimen que sugiero llamar (reconocer como) autocracia electiva (p. 338).

El plantear la interrogante de una factible democracia sin elecciones implica inevitablemente hacer alusión a la democracia participativa como alternativa de decisión colectiva, y entre cuyas prácticas se encuentran el presupuesto participativo y la participación colaborativa (primordialmente crítica y contrastante), ubicada contextualmente en el entorno del denominado movimiento de los movimientos, que tiene como característica la inclusión democracia directa y delegada en el proceso decisorio de índole político (Bovero, 2012).

Ello conduce a Bovero (2012) a aseverar que "la deliberación que debe preceder a la decisión política final requiere que la discusión sea inclusiva, no selectiva; y efectiva, no meramente casual y eventual" (p. 348).

A manera de conclusión, Bovero (2012) plantea que "una democracia representativa no deliberativa está vacía y corre el riesgo de degenerar en la oligarquía (o una monocracia, o una pleonocracia) autocrítica. Una democracia deliberativa no representativa está ciega y corre el riesgo de convertirse en una peligrosa ilusión” (p. 340).

No se debe pasar por alto la realidad que afronta la democracia deliberativa, ya que se ha limitado a adoptar instituciones y mecanismos de la democracia liberal, complementados con una creciente inserción de elementos de participación ciudadana, espacio y opinión pública, con la finalidad de despresurizar la tensión entre la democracia y el liberalismo, pero que aún debe afrontar la problemática de definir al responsable de tomar las decisiones de carácter vinculante y garantizar la eficacia y eficiencia de las expectativas de resultados producto de la deliberación. 
Revista Iberoamericana

de las Ciencias Sociales y

Humanísticas

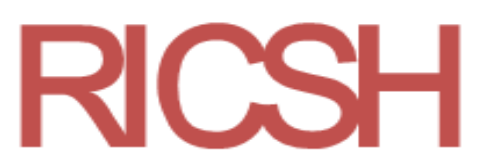

ISSN: $2395-7972$

\section{Marcos teórico y conceptual inherentes a \\ derechos humanos, democracia, y consultas públicas \\ Marco teórico}

Sobre la base de un primer sustento teórico, la democracia como ideología pertenece al rubro de los derechos humanos, lo que legitima su importancia y trascendencia social. Consolidada a partir de la adopción de la Declaración Universal sobre la Democracia por el Consejo Interparlamentario de la Unión Interparlamentaria (UIP) por la Democracia para todos (1997), con motivo de su 161. a sesión celebrada en El Cairo, Egipto, en fecha 16 de septiembre de 1997, resaltan por su importancia los principios consagrados en sus artículos $1,2,3$ y 18, que se transcriben a continuación.

1. La democracia es un ideal universalmente reconocido y un objetivo basado en valores comunes a todos los pueblos que conforman la comunidad mundial, independientemente de las diferencias culturales, políticas, sociales y económicas. Por lo tanto, es un derecho fundamental del ciudadano, que debe ejercerse en condiciones de libertad, igualdad, transparencia y responsabilidad, con respeto a la pluralidad de opiniones y al interés común.

2. La democracia es tanto un ideal a perseguir como un modo de gobierno que se aplica de manera que refleje la diversidad de experiencias y particularidades culturales, sin apartarse de los principios, estándares y reglas internacionalmente reconocidos. Por lo tanto, es un estado o condición, constantemente perfeccionado y siempre perfectible, cuya evolución depende de varios factores, políticos, sociales, económicos y culturales.

3. Como ideal, la democracia esencialmente tiene como objetivo preservar y promover la dignidad y los derechos fundamentales del individuo, garantizar la justicia social, promover el desarrollo económico y social de la comunidad y fortalecer la cohesión de la sociedad. esa tranquilidad nacional y crear un clima propicio para la paz internacional. Como forma de gobierno, la democracia es la mejor manera de lograr estos objetivos; También es el único sistema político capaz de corregirse.

18. Si la existencia de una sociedad civil activa es un elemento esencial de la democracia, la capacidad y la voluntad de las personas para participar en los 


\section{Revista Iberoamericana de las Ciencias Sociales y Humanísticas}

ISSN: $2395-7972$

procesos democráticos y elegir los métodos de gobierno no son evidentes. Por lo tanto, es necesario crear condiciones propicias para el ejercicio efectivo de los derechos participativos, al tiempo que se eliminan los obstáculos que impiden o limiten dicho ejercicio. Por lo tanto, es esencial promover constantemente, en particular, la igualdad, la transparencia y la educación, y eliminar obstáculos, como la ignorancia, la intolerancia, la apatía, la falta de opciones y alternativas genuinas y la ausencia de medidas para corregir los desequilibrios y la discriminación social, cultural, religiosa, racial o de género (Annexe VII).

Es justamente en ese este artículo 18 que encontramos cabida justificativa a las consultas públicas a efecto de poner en ejercicio los derechos participativos al tener derecho a que se instauren condiciones propicias y supresión de obstáculos que lo limiten o impidan 6 .

A partir de una segunda influencia teórica, analicemos la funcionalidad de las consultas públicas a partir de la Guía para la elaboración de constituciones preparada por un “Constitutionmaker” de la Organización de las Naciones Unidas (ONU) (2013-2019). Las consultas públicas se realizan como parte del proceso constitucional para buscar activamente los aportes de la ciudadanía y de grupos organizados sobre el contenido del texto constitucional y el proceso de elaboración de la Constitución política de un país, de esta manera las consultas públicas se constituyen como mecanismos de retroalimentación bidireccional para dar la debida consideración a los aportes informados de los ciudadanos y para permitir a estos comprender las decisiones reflejadas en la ley suprema sea nueva o revisada.

En la elaboración de la constitución las consultas públicas son de gran soporte, pues con ello se determina si los ciudadanos apoyan o no su confección, se le pregunta a la sociedad sobre sus necesidades y prioridades que deben de ser reflejados en dicha carta magna, se fomenta el diálogo y discusión a nivel nacional sobre temas políticos, sociales y económicos, se expande la discusión sobre el contenido más allá de lo que lo harían los políticos, facilita al órgano constituyente contar con ideas de un amplio número de personas que pueden aportar opciones innovadoras, se fomenta la confianza entre los ciudadanos y sus líderes y se enseñan los principios y prácticas de la democracia.

${ }^{6}$ Sobre la protección de los derechos fundamentales se sugiere analizar la obra de Hernández Valle, R. (1990). La tutela de los derechos fundamentales (1. ${ }^{a}$ ed.). San José, Costa Rica: Juricentro. 


\section{Revista Iberoamericana de las Ciencias Sociales y Humanísticas}

ISSN: $2395-7972$

Lo ideal es que las consultas públicas incluyan a la mayoría de la población o por lo menos a todos los interesados desde un principio, o a quienes irá dirigido o determinado cierto apartado de la Constitución, por lo que se deben de considerar categorías generales y enfoques especiales ${ }^{7}$.

De trascendencia para la credibilidad de la consulta es quién la realiza, pues puede hacerlo el propio órgano constituyente, un órgano independiente que lo realiza a través de mandato oficial, los funcionarios locales o las organizaciones de la sociedad civil. Dependiendo del estatus que cada órgano guarde ante la sociedad, será la aceptación y credibilidad del resultado de la consulta y, por tanto, la conformidad que tendrá la comunidad respecto de lo redactado en la constitución resultado de la consulta realizada ${ }^{8}$.

Las consultas pueden ser desestructuradas, semiestructuradas o estructuradas. Resulta imprescindible en las consultas públicas comunicar a los ciudadanos cómo fueron utilizadas las aportaciones de los ciudadanos; de esta manera, se asegura que la gente perciba el proceso como legítimo. Por tanto, debe de comunicarse a quién se realizó la consulta, cuáles fueron las aportaciones de la ciudadanía más recurrentes, cuáles aportes dieron lugar a cambios y por qué y qué cambios no se realizaron, y cuáles fueron las razones 9 .

Un tercer sustento teórico se encuentra soportado en la consulta recíprocamente vinculante o mutually binding consultation, dada su considerable relevancia e influencia inspiradora. En el espacio de reflexión destinado a los elementos de la democracia, democratización y desdemocratización, Tilly (2007) nos comparte la importancia de las opiniones, necesidades y demandas que formulan los ciudadanos en un régimen democrático, y hace una alusión particular a la consulta recíprocamente vinculante. Veamos su opinión conforme a la traducción que nos permitimos realizar al efecto:

\footnotetext{
${ }^{7}$ Verificar en ese aspecto la obra de Casado, L. (2018). La aplicación del trámite de consulta pública previa en el procedimiento de elaboración de normas locales dos años después de su entrada en vigor. Revista Aragonesa de Administración Pública, (52), 159-210.

${ }^{8}$ En materia de participación de la sociedad civil, se recomienda revisar a Milano, A. y Zanhueza, A. (2016). Consultas públicas con sociedad civil: guías para agencias ejecutoras públicas y privadas (1. ${ }^{\mathrm{a}}$ ed.). (B. I. Desarrollo, Ed.) Banco Interamericano de Desarrollo.

${ }^{9}$ Para profundizar en la aportación ciudadana en dicha elaboración se recomienda revisar la obra de García García, M. D. (2008). La participación ciudadana en la elaboración de disposiciones reglamentarias. Participación funcional e iniciativa reglamentaria. Revista Catalana de Dret Públic RCDP, (37), 416-460, así como García, M. D. (2008). La participación ciudadana en la elaboración de disposiciones reglamentarias: participación funcional e iniciativa reglamentaria. v lex Información Jurídica Inteligente, 419-156.
}

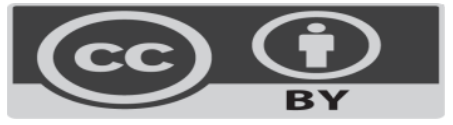


Revista Iberoamericana

de las Ciencias Sociales y

Humanísticas

ISSN: 2395 - 7972

Parte de la política pública consiste en consultar a los ciudadanos sobre sus opiniones, necesidades y demandas. La consulta incluye cualquier medio público porque ciudadanos expresan sus preferencias colectivas con respecto al personal del estado y políticas. En regímenes relativamente democráticos, elecciones competitivas, ciertamente les da voz a los ciudadanos, pero también lo hacen los grupos de presión, peticiones, referéndums, movimientos sociales y encuestas de opinión. Esta vez las complicaciones faltantes son obvias: sobornos, cadenas de patrones y clientes, favores a los constituyentes y seguidores, conexiones de parentesco entre funcionarios y fenómenos similares desenfocan el límite entre la política pública y privada (p. 13).

De igual manera, este tratadista se refiere a los dos espacios límites de la democracia; estos son la democratización que implica una tendencia acrecentadora de la consulta (para tornarla más amplia, considerablemente más igualitaria, más sujeta de protección y por consiguiente más vinculante), y la desdemocratización que implica la contracción de dichos fenómenos.

La justa ponderación de la consulta vinculante en un régimen democrático es aquilatada por Tilly (2007) al concluir:

Para nuestros propósitos, un régimen es democrático en la medida en que las relaciones políticas entre el estado y sus ciudadanos presentan características amplias, iguales, protegidas y consulta mutuamente vinculante. En consecuencia, la democratización consiste en un movimiento del régimen hacia ese tipo de consulta, desmocratización el movimiento de un régimen lejos de él (p. 189).

Es en el análisis económico del derecho o Economic analysis of law donde localizamos el cuarto soporte teórico de esta investigación, aprovechando al respecto los aportes de Coase (1960), Calabresi (1970), Cooter y Ulen (2016) y Cossío (2015). En la temática de este trabajo investigativo, el empleo de la economía radica en que esta promete una teoría científica para presagiar los efectos de las normas legales sobre el comportamiento de las instituciones que organizan las consultas públicas y los ciudadanos que ejercerán el derecho de pronunciarse democráticamente mediante su participación en aquellas. Estamos situados entonces en la esfera de la economía donde se valorará el costo-beneficio de la 


\section{Revista Iberoamericana \\ de las Ciencias Sociales y Humanísticas}

ISSN: 2395 - 7972

implementación de las consultas públicas para compensar en algo los vicios de la falta de participación y, por ende, de legitimación existentes en la democracia directa.

Ahora bien, en lo que concierne a los aportes que el análisis económico del derecho puede prometer a la temática afrontada en esta investigación, predominan la implementación o adecuación de políticas públicas a través de herramientas de índole económico ${ }^{10}$ y la justipreciación del costo-beneficio que tendría la adaptación de la norma jurídica a la realidad dominante en la participación democrática del ciudadano mediante el ejercicio de las consultas públicas, de su futuro como mecanismo de legitimación de la democracia y su posible consolidación como utensilio recurrente en asuntos de trascendencia nacional, ya que podrían resultar una fuente optimizadora de recursos presupuestales, ello a partir de la comprensión de los factores ajustados a la economía, mitigando así el riesgo de continuar operando un régimen democrático caduco ante la actual carencia de legitimidad derivado de vicios o crisis democrática, tales como la partidocracia, consociativismo, autocracia electiva, pleonocracia, populismo, así como afrontar los principales retos de los partidos políticos que se anuncian a lo largo de esta investigación.

\section{Marco conceptual conveniente para el estudio de las instituciones que se evocan en este estudio investigativo}

El primer concepto a desentrañar es el relativo a los derechos humanos; en tal sentido, y atendiendo a la aportación de Nogueira (2003), podríamos decir:

El concepto de derechos humanos, en el contexto contemporáneo, se reserva generalmente para denominar a los derechos de la persona, reconocidos y garantizados por el derecho internacional, sea este consuetudinario o convencional (derecho internacional de los derechos humanos y derecho internacional humanitario). Muchas veces el concepto se extiende a los derechos constitucionales (p. 58).

Un segundo concepto de relevancia para nuestra investigación lo localizamos en la democracia. En su compilación sobre el estudio de la interacción entre la democracia y el

10 Requerimiento que ha venido colmando la Organización para la Cooperación y Desarrollo Económicos (OCDE) (2017). Estudio de gobernanza pública de la OCDE. Chile. Informe 2017. Crear un entorno propicio para un OCDE Mejores Políticas para una Vida Mejor., 36. 
Revista Iberoamericana

de las Ciencias Sociales y

Humanísticas

ISSN: $2395-7972$

desarrollo la Organización de las Naciones Unidas para la Educación, la Ciencia y la Cultura (Unesco) a través de Buotros-Ghali (2003), considera:

La democracia puede definirse en suma como un sistema político capaz de corregir sus propias disfunciones. Pero una auténtica democracia no puede limitarse en ningún caso a un simple entramado institucional, sino que debe plasmarse también en una cultura, un talante que propicie la tolerancia, el respeto por el prójimo, el pluralismo, el equilibrio y el diálogo entre las fuerzas constitutivas de la sociedad (pp. 7-8).

La participación representa el tercer concepto trascendente en esta investigación. Conforme al Proyecto de Guía para Educadores Pares formulado por Konrad-AdenauerStiftung (KAS) a través de su Oficina en Uganda (2011), en calidad de acción para fortalecer el buen gobierno y rendición de cuentas de dicho país, y bajo el auspicio de la Unión Europea, identificamos concebida a la participación como un ingrediente funcional de la democracia, afirmando que "la participación es un componente de la democracia que se refiere al proceso por el cual las personas actúan de manera política para conectarse con el gobierno y así convertirse en autogobernantes" (p. 15).

El último concepto para analizar en este trabajo lo identificamos en las consultas públicas. Como resultado de lo indagado en el cuadro de la democracia y sus variantes, nos permitimos acuñar el siguiente concepto de consulta pública: una modalidad de puesta en ejercicio de los derechos de participación democrática que sirven como instrumento de búsqueda activa de los aportes de la ciudadanía y de grupos organizados con respecto a temas relevantes de un país, cuya utilidad consiste en retroalimentar bidireccionalmente a efecto de legitimar y comprender las decisiones adoptadas en función a las necesidades identificadas y prioridades focalizadas fomentando con ello la confianza de los ciudadanos al tener la oportunidad de discutir, planificar y decidir sobre los temas materia de consulta, en el entendido de que su eficacia y eficiencia dependerá de la existencia y ejecución adecuada del respectivo plan operacional. 


\section{Revista Iberoamericana \\ de las Ciencias Sociales y \\ Humanísticas}

ISSN: $2395-7972$

\section{La regulación normativa de las consultas públicas en México}

\section{La Constitución Política de los Estados Unidos Mexicanos}

Los artículos de la Constitución Política de los Estados Unidos Mexicanos (1917) que contienen las disposiciones relevantes para esta búsqueda investigativa son los que en forma sintetizada se citan a continuación:

En el ámbito de los derechos humanos, el artículo 1. prevé su tutela y las garantías para su protección, así como el principio pro persona, la obligación para las autoridades de promoverlos, respetarlos, protegerlos y garantizarlos, conforme a los principios de universalidad, interdependencia, indivisibilidad y progresividad.

En materia de derechos de las comunidades indígenas ${ }^{11}$ a pronunciarse mediante consulta, el artículo segundo reconoce la obligación del estado mexicano de definir y desarrollar programas educativos de contenido regional que reconozcan la herencia cultural de sus pueblos, de acuerdo con las leyes de la materia y en consulta con las comunidades indígenas, así como consultar a los pueblos indígenas en la elaboración del Plan Nacional de Desarrollo y de los planes de las entidades federativas, de los municipios y, cuando proceda, de las demarcaciones territoriales de la Ciudad de México y, en su caso, incorporar las recomendaciones y propuestas que realicen ${ }^{12}$.

En el ramo del acceso a la información pública y la protección de datos personales, el artículo 6, inciso A, fracción VIII, determina que para el nombramiento de comisionado del organismo autónomo (especializado, imparcial, colegiado, con personalidad jurídica y patrimonio propio, con plena autonomía técnica, de gestión, capacidad para decidir sobre el ejercicio de su presupuesto y determinar su organización interna) responsable de garantizar el cumplimiento de ese derecho, la Cámara de Senadores lo nombrará, previa realización de una amplia consulta a la sociedad, a propuesta de los grupos parlamentarios, con el voto de las dos terceras partes de los miembros presentes.

${ }^{11} \mathrm{La}$ protección a este sector que es ampliamente abordada por la Organización Internacional del Trabajo (OIT) (1989). Manual para los mandantes tripartitos de la OIT (vol. 169), así como por la Oficina Internacional del Trabajo (2016). Procedimientos para la celebración de consultas con los pueblos indígenas. Experiencia de Noruega (1. ${ }^{\mathrm{a}}$ ed.). Ginebra, Suiza:

12 Desde una perspectiva jurisprudencial y para profundizar en su estudio, se sugiere consultar TEPJF, T. E. (2014). Democracia igualitaria. Criterios jurisprudenciales para la equidad de género y la inclusión de comunidades indígenas (T. Coordinación de Comunicación Social, Ed.) México: Tribunal Electoral del Poder Judicial de la Federación. 


\section{Revista Iberoamericana}

de las Ciencias Sociales y Humanísticas

ISSN: $2395-7972$

En lo que concierne al sector de radiodifusión y telecomunicaciones, la designación

por el Senado de la República de los consejeros honorarios que integrarán el Consejo Ciudadano del Sistema Público de Radiodifusión del Estado Mexicano, el artículo 6, inciso $\mathrm{B}$, fracción $\mathrm{V}$, establece que se deberá efectuar previa la aplicación de una amplia consulta pública.

En lo relacionado con la planeación democrática, el artículo 26, inciso A, estipula que la ley facultará al Ejecutivo para que establezca los procedimientos de participación y consulta popular en el sistema nacional de planeación democrática, y los criterios para la formulación, instrumentación, control y evaluación del plan y los programas de desarrollo.

Los derechos del ciudadano a votar en las elecciones populares, poder ser votado para todos los cargos de elección popular; y votar en las consultas populares sobre temas de trascendencia nacional son tutelados respectivamente por las fracciones I, II, y VIII del artículo 35.

En cuanto a las temáticas exceptuadas de la aplicación de las consultas populares, la precitada fracción VIII del artículo 35 establece que no podrán ser objeto de consulta popular la restricción de los derechos humanos reconocidos por esta Constitución, los principios consagrados en el artículo 40 de esta, la materia electoral, los ingresos y gastos del Estado.

La seguridad nacional y la organización, funcionamiento y disciplina de la Fuerza Armada permanente, confiriendo a la Suprema Corte de Justicia de la Nación la potestad de resolver, previo a la convocatoria que realice el Congreso de la Unión, sobre la constitucionalidad de la materia de la consulta.

La obligación a cargo del ciudadano de la República de votar en las elecciones y en las consultas populares se encuentra establecida en la fracción III del artículo 36.

En cuanto al ejercicio de la soberanía popular, el artículo 39 precisa que ese derecho reside esencial y originariamente en el pueblo, y que todo poder público dimana del pueblo y se instituye para beneficio de este, quien tiene en todo tiempo el inalienable beneficio de alterar o modificar la forma de su gobierno.

Sobre la forma de gobierno, el artículo 40 es contundente al subrayar que la voluntad del pueblo mexicano es constituirse en una República representativa, democrática, laica y federal, compuesta por Estados libres y soberanos en todo lo concerniente a su régimen interior, y por la Ciudad de México, unidos en una federación. 
Revista Iberoamericana

de las Ciencias Sociales y

Humanísticas

ISSN: $2395-7972$

Las bases para la renovación de los poderes Legislativo y Ejecutivo mediante elecciones libres, auténticas y periódicas son fijadas por el artículo 41.

Las facultades del Congreso de la Unión para legislar sobre iniciativa ciudadana y consultas populares, así como para expedir las leyes generales que distribuyan competencias entre la Federación y las entidades federativas en materias de partidos políticos; organismos electorales y procesos electorales están conferidas al tenor de las fracciones XXIX-Q, y XXIX-U del artículo 73.

En lo tocante al procedimiento de consulta pública a seguir para la elección del titular de la presidencia de la Comisión Nacional de los Derechos Humanos, así como de los integrantes del Consejo Consultivo, y de titulares de los organismos de protección de los derechos humanos de las entidades federativas, el mismo se prevé por el inciso B, del artículo 102.

\section{La Ley Federal de Consulta Popular}

El objeto fundamental de la Ley Federal de Consulta Popular (14 de marzo de 2014) es la regulación del procedimiento para la convocatoria, organización, desarrollo, cómputo y declaración de resultados de la consulta popular y promover la participación ciudadana en las consultas populares (artículos 1, 2 y 3).

Este ordenamiento concibe a la consulta popular como un "mecanismo de participación por el cual los ciudadanos ejercen su derecho, a través del voto emitido mediante el cual expresan su opinión respecto de uno o varios temas de trascendencia nacional" (artículo 4).

Son solamente temas de trascendencia nacional los que caen bajo el imperio de la consulta popular, y su calificación corresponde a la mayoría de los legisladores presentes en cada Cámara, excepción hecha de la consulta que surge de la propuesta ciudadana donde el carácter relevante es resuelto por la Suprema Corte de Justicia de la Nación (artículo 5), y los parámetros de determinación de relevancia son (i) que repercutan en la mayor parte del territorio nacional y (ii) que impacten en una parte significativa de la población (artículo 6).

Un aspecto a resaltar es el carácter vinculante de la consulta popular, y este se presenta solamente cuando la participación total corresponda, al menos, al cuarenta por ciento de los ciudadanos inscritos en la lista nominal de electores (artículo 5). 
Revista Iberoamericana

de las Ciencias Sociales y

Humanísticas

ISSN: 2395 - 7972

En lo concerniente a los temas exceptuados de consulta popular, se abstraen de este mecanismo de consulta la restricción de los derechos humanos reconocidos por la Constitución Política de los Estados Unidos Mexicanos; los principios consagrados en el artículo 40 de la Constitución Política de los Estados Unidos Mexicanos; la materia electoral; los ingresos y gastos del Estado; la seguridad nacional, y la organización, funcionamiento y disciplina de la Fuerza Armada permanente (artículo 11).

En cuanto a la petición misma de consulta popular, ella se limita al presidente de la República; al equivalente al treinta y tres por ciento de los integrantes de cualquiera de las Cámaras del Congreso, o a los ciudadanos en un número equivalente, al menos, al dos por ciento de los inscritos en la lista nominal de electores (artículo 12).

\section{Factibilidad de que el régimen mexicano de consultas públicas permita su regulación y ejercicio con eficacia y eficiencia}

Para constatar dicha factibilidad debemos emprender el análisis de la transición de una democracia participativa hacia una democracia justificativa.

Coincidiendo con el criterio de Peña (2009) — con motivo de su análisis conceptual en el espacio de la dictadura, la democracia y la república (particularmente en lo concerniente a otros tipos de democracia) — difícilmente será posible considerar a las consultas públicas como la panacea de la democracia, al menos no en la forma en que se encuentran reguladas y aplicadas en México.

A continuación, la opinión del autor en cita al referirse especialmente a la democracia participativa y a la democracia justificativa. No deja de reconocer Peña (2009), y de hecho marca hasta mordazmente el acento, en una serie de inconvenientes de la puesta en ejercicio de la democracia participativa: sus ambiguas y en ocasiones inexistentes reglas de aplicación en el plano fáctico (amén de lo impreciso en cuanto a considerársele como complementaria de la democracia directa o sustitutiva de ella), que polarizó aún más el poder, ya que termina por quedar relegado un gran conglomerado incógnito de población al preponderar el peso de la ciudadanía organizada, de los profesionales en la práctica del cabildeo, de los elocuentes, influyentes y hasta vociferantes, y que se corre el riesgo de llegar a la concentración de poder fáctico en virtud de quienes lo detentan para incrementar las posibilidades de aplicar contundentemente su predominio. 


\section{Revista Iberoamericana de las Ciencias Sociales y Humanísticas}

ISSN: $2395-7972$

Ante el cuestionamiento de la eficacia en la adopción de la democracia participativa, sensatamente Peña (2009) advierte la necesidad de identificar una nueva alternativa que denomina democracia justificativa, la cual es explicada con la adopción de decisiones correctas que evidencien justificadamente el respeto de los valores consagrados como supremos por la población predominante, lo que suprimirá cualquier rasgo de injusticia, ya que el votante asumirá la responsabilidad de justificar el sentido de su determinación. En ese modelo de democracia justificativa, el propio votante ha de justificar su voto.

Según Peña (2009), cinco son las características del modelo propuesto: toda determinación deberá encontrarse plenamente justificada, inclusive o principalmente el voto; procedimiento electoral adecuado conforme a la opinión pública; supresión de poderes fácticos injustificados (tanto de las mayorías como de las minorías); control del pluralismo, y documentar fehacientemente la asunción de compromisos.

Compartiendo el criterio de Sáenz y Rodríguez (2010), se puede considerar que en la democracia participativa los ciudadanos deben mantenerse en permanente actividad soportada en información que los haga tomar determinaciones con racionalidad, tanto en lo que se refiere a la elección de sus candidatos como en su participación activa en las funciones de representación. El desarrollo de una verdadera cultura política, el ejercicio de debates públicos y la aplicación de consultas públicas permitirán la conjunción de diferentes puntos de vista, lo que otorgará una posibilidad de llegar a un consenso suficientemente argumentado.

Es justamente por ello que al evocar el ideal democrático en el capítulo destinado a la concepción democrática de la educación, Dewey (1998) admite la existencia de medios conductores hacia el correcto camino de la democracia:

Los dos elementos de nuestro criterio se dirigen hacia la democracia. El primero significa no solo puntos más numerosos y más variados de interés participados en común, sino también el reconocimiento de los intereses mutuos como un factor del control social. El segundo significa no solo una interacción más libre entre los grupos sociales (antes aislados donde la intención podrá mantener una separación), sino también un cambio en los hábitos sociales; su reajuste continuo afrontando las nuevas situaciones producidas por el intercambio variado. Y estos dos rasgos son precisamente los que caracterizan a la sociedad democráticamente constituida (p. 81). 


\section{Revista Iberoamericana de las Ciencias Sociales y Humanísticas}

\section{Discusión}

Para explicar la discusión de los resultados de esta investigación elaboramos de nuestra autoría una tabla que precisa (i) el significado de los hallazgos; (ii) la respuesta de los hallazgos a la pregunta de investigación e hipótesis; (iii) las limitaciones al estudio de las consulta públicas; (iv) la influencia de los hallazgos en los resultados; (v) la relación de los hallazgos con los estudios realizados anteriormente; (vi) las implicaciones del estudio para los investigadores, practicantes o legisladores, y (vii) las sugerencias para futuras investigaciones basadas en los hallazgos.

Tabla 1. Discusión de los resultados

\begin{tabular}{|c|c|c|c|c|c|c|}
\hline $\begin{array}{l}\text { 1. Significa- } \\
\text { do de los } \\
\text { hallazgos }\end{array}$ & $\begin{array}{c}\text { Respues-ta } \\
\text { de los } \\
\text { hallazgos a } \\
\text { la pregunta } \\
\text { de } \\
\text { investigación } \\
\text { o hipótesis }\end{array}$ & $\begin{array}{c}\text { Limitaciones al } \\
\text { estudio de las } \\
\text { consultas públicas }\end{array}$ & $\begin{array}{c}\text { Influencia } \\
\text { de los } \\
\text { hallazgos en } \\
\text { los } \\
\text { resultados }\end{array}$ & $\begin{array}{l}\text { Relación de } \\
\text { los hallazgos } \\
\text { con estudios } \\
\text { realizados } \\
\text { anterior- } \\
\text { mente }\end{array}$ & $\begin{array}{c}\text { Implica- } \\
\text { ciones del } \\
\text { estudio } \\
\text { para } \\
\text { investiga- } \\
\text { dores, } \\
\text { practicantes } \\
\text { o legislado- } \\
\text { res }\end{array}$ & $\begin{array}{c}\text { Sugeren- } \\
\text { cias para } \\
\text { futuras } \\
\text { investiga- } \\
\text { ciones } \\
\text { basadas } \\
\text { en los } \\
\text { hallaz-gos }\end{array}$ \\
\hline $\begin{array}{l}\text { A). Se } \\
\text { identifica- } \\
\text { ron (i) los } \\
\text { sustentos } \\
\text { jurídicos, } \\
\text { filosóficos y } \\
\text { sociológi- } \\
\text { cos de los } \\
\text { derechos } \\
\text { humanos } \\
\text { (Nogueira, } \\
\text { 2003; Alexy, } \\
\text { 1997; } \\
\text { Ferrajoli, } \\
\text { 2004); (ii) la } \\
\text { historicidad } \\
\text { de la } \\
\text { democra- } \\
\text { cia, y (iii) el } \\
\text { origen de los } \\
\text { soportes } \\
\text { normativos } \\
\text { de las } \\
\text { consultas }\end{array}$ & $\begin{array}{l}\text { Se confirma } \\
\text { la siguiente } \\
\text { hipótesis: la } \\
\text { democra-cia } \\
\text { es un } \\
\text { principio } \\
\text { elemental de } \\
\text { los derechos } \\
\text { humanos, y } \\
\text { responde a la } \\
\text { pregunta de } \\
\text { que las } \\
\text { consultas } \\
\text { públicas son } \\
\text { una de las } \\
\text { formas de } \\
\text { acercar la } \\
\text { democra-cia } \\
\text { al colectivo } \\
\text { social, pero } \\
\text { su legitima- } \\
\text { ción depende } \\
\text { de la debida } \\
\text { regulación de }\end{array}$ & $\begin{array}{l}\text { Se refieren } \\
\text { preponderantemente } \\
\text { al aspecto } \\
\text { dogmático sin que } \\
\text { hubiere resultado } \\
\text { factible: identificar } \\
\text { estudios sobre su } \\
\text { aplicación } \\
\text { pragmática } \\
\text { develen numérica- } \\
\text { mente su grado de } \\
\text { eficacia y eficiencia. }\end{array}$ & $\begin{array}{l}\text { A). } \\
\text { Permitieron } \\
\text { identificar } \\
\text { las bases } \\
\text { normativas, } \\
\text { filosóficas y } \\
\text { sociológicas } \\
\text { de los } \\
\text { derechos } \\
\text { humanos, la } \\
\text { democracia y } \\
\text { las consultas } \\
\text { públicas. } \\
\text { B). } \\
\text { Facilitaron la } \\
\text { compren- } \\
\text { sión de los } \\
\text { postulados } \\
\text { de la } \\
\text { Declara-ción } \\
\text { Universal } \\
\text { sobre la } \\
\text { Democra- } \\
\text { cia; la } \\
\text { consulta }\end{array}$ & 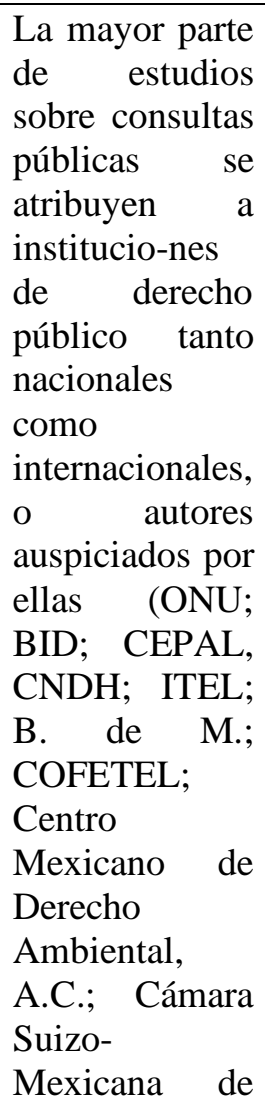 & $\begin{array}{l}\text { Les } \\
\text { permitirán la } \\
\text { compren- } \\
\text { sión de los } \\
\text { funda- } \\
\text { mentos de } \\
\text { los derechos } \\
\text { humanos; } \\
\text { el concepto y } \\
\text { evolución de } \\
\text { la democra- } \\
\text { cia para } \\
\text { establecer si } \\
\text { esta es } \\
\text { contenido } \\
\text { esencial de } \\
\text { aquellos, si } \\
\text { su inclusión } \\
\text { posibilita la } \\
\text { satisfac-ción } \\
\text { de } \\
\text { una na su } \\
\text { necesidad } \\
\text { real, o su } \\
\text { omisión o }\end{array}$ & $\begin{array}{l}\text { Enfocar la } \\
\text { atención en } \\
\text { el estudio } \\
\text { del modelo } \\
\text { de la } \\
\text { democracia } \\
\text { justifi- } \\
\text { cativa. }\end{array}$ \\
\hline
\end{tabular}


Revista Iberoamericana

de las Ciencias Sociales y Humanísticas

ISSN: $2395-7972$

\begin{tabular}{|c|c|c|c|c|}
\hline 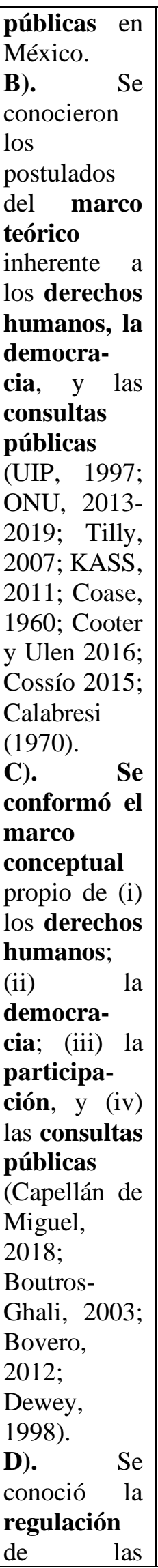 & $\begin{array}{l}\text { los } \\
\text { resultados. }\end{array}$ & $\begin{array}{l}\text { recíproca- } \\
\text { mente } \\
\text { vinculante y } \\
\text { el análisis } \\
\text { económi-co } \\
\text { del Derecho. } \\
\text { C). } \\
\text { Auxiliaron } \\
\text { en la } \\
\text { conforma- } \\
\text { ción de un } \\
\text { marco } \\
\text { concep-tual } \\
\text { de los } \\
\text { derechos } \\
\text { humanos, la } \\
\text { democra-cia } \\
\text { y de las } \\
\text { consultas } \\
\text { públicas. } \\
\text { D). Permitie- } \\
\text { ron localizar } \\
\text { en la } \\
\text { Constitución } \\
\text { Federal los } \\
\text { supuestos de } \\
\text { las consultas } \\
\text { públicas y la } \\
\text { compren- } \\
\text { sión de la } \\
\text { Ley Federal } \\
\text { de Consulta } \\
\text { Popular. } \\
\text { E). la } \\
\text { Coadyuvaron } \\
\text { en democra- } \\
\text { conforma- } \\
\text { ción de } \\
\text { conclu- } \\
\text { siones } \\
\text { formula-ción } \\
\text { de } \\
\text { propuesta de } \\
\text { la democifica- } \\
\text { cia justific } \\
\text { tiva. }\end{array}$ & $\begin{array}{l}\text { Comercio e } \\
\text { Industria, A.C.; } \\
\text { INE, Congreso } \\
\text { de la Unión, } \\
\text { etc.). }\end{array}$ & $\begin{array}{l}\text { ausencia } \\
\text { tiene } \\
\text { implica- } \\
\text { ciones } \\
\text { negativas } \\
\text { para el } \\
\text { correcto y } \\
\text { óptimo } \\
\text { desarrollo y } \\
\text { progreso de } \\
\text { la vida } \\
\text { social, } \\
\text { preten- } \\
\text { diendo } \\
\text { determi-nar } \\
\text { si es a través } \\
\text { de las } \\
\text { consultas } \\
\text { públicas que } \\
\text { se acerca el } \\
\text { derecho } \\
\text { humano de } \\
\text { la } \\
\text { democracia } \\
\text { a } \\
\text { sociedad. }\end{array}$ \\
\hline
\end{tabular}


Revista Iberoamericana

de las Ciencias Sociales y Humanísticas

ISSN: $2395-7972$

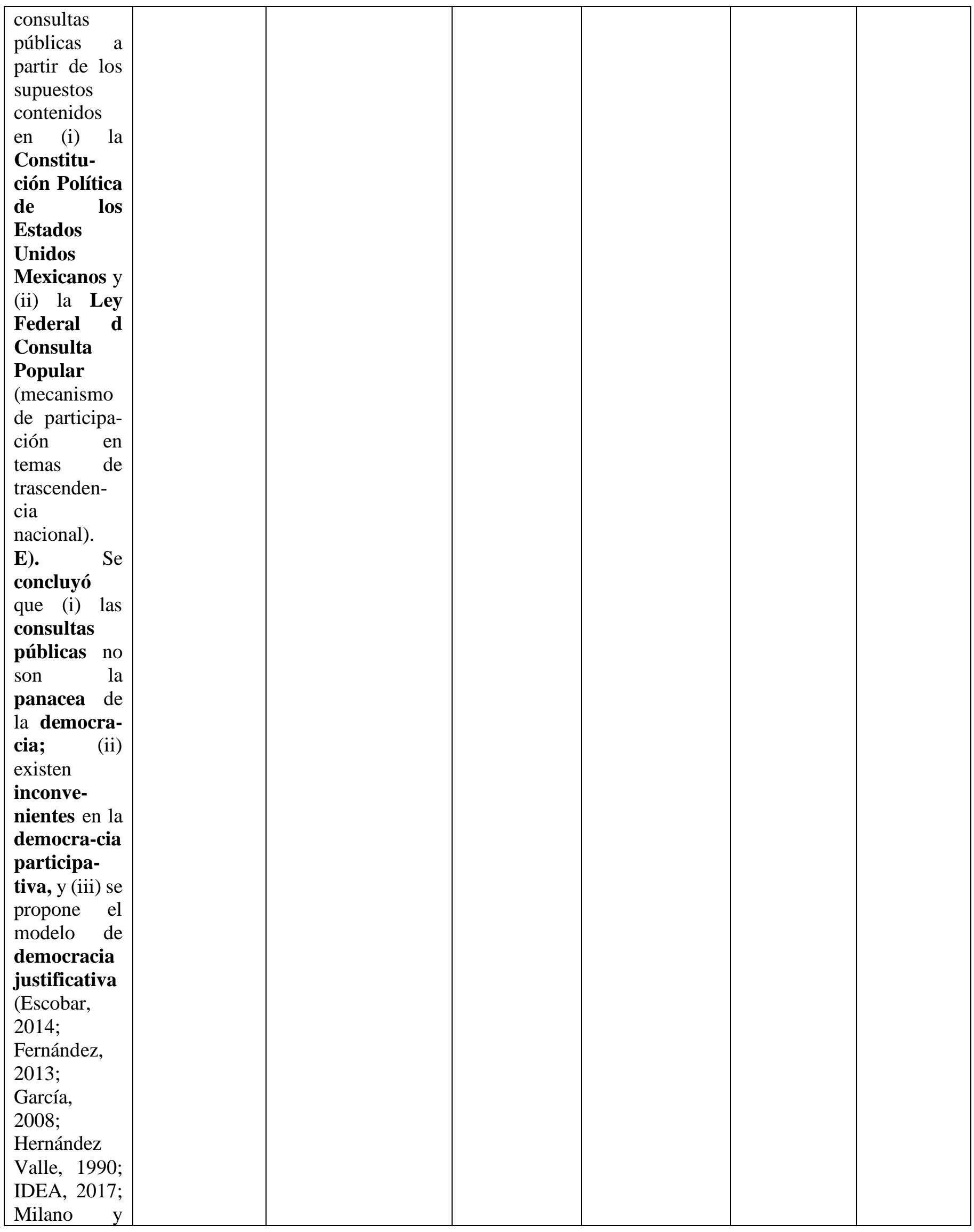


Revista Iberoamericana

de las Ciencias Sociales y

Humanísticas

ISSN: $2395-7972$

\begin{tabular}{|l|l|l|l|l|l|}
\hline Zanhueza, & & & & \\
2016; & & & & & \\
Prud'homme, & & & & & \\
2016; Sáenz & & & & \\
y Rodríguez, & & & & \\
2010; & & & & \\
Sartori, & & & & \\
2009). & & & & \\
\hline
\end{tabular}

Fuente: Elaboración propia

\section{Conclusiones}

Se identificó la naturaleza jurídica de las consultas públicas en una dualidad, pues se concibieron no solamente como derecho, sino también como obligación, a la que se le brinda el tratamiento de una variable del ejercicio democrático, admitiendo, además, la posibilidad de asemejar los términos consulta pública y consulta popular.

Las consultas públicas son conceptualizadas como una modalidad de puesta en ejercicio de los derechos de participación democrática que sirven como instrumento de búsqueda activa de los aportes de la ciudadanía y de grupos organizados con respecto a temas relevantes de un país, cuya utilidad consiste en retroalimentar bidireccionalmente a efecto de legitimar y comprender las decisiones adoptadas en función a las necesidades identificadas y prioridades focalizadas, fomentando con ello la confianza de los ciudadanos al tener la oportunidad de discutir, planificar y decidir sobre los temas materia de consulta, en el entendido de que su eficacia y eficiencia dependerá de la existencia y ejecución adecuada del respectivo plan operacional.

Asimismo, fue factible determinar sus alcances o efectos al versar sobre temas de trascendencia nacional, aunque resulta cuestionable la mecánica para comprobar el carácter relevante de un tópico sujeto a dicho instrumento.

Sus ventajas radican en legitimar y comprender las determinaciones tomadas con soporte en las necesidades focalizadas y prioridades establecidas, lo que fomenta la confianza de los ciudadanos, quienes tienen la alternativa de participar en tareas de discusión, planificación y decisión.

Se hicieron visibles sus inconvenientes al corroborar la inexistencia de un adecuado plan operacional y la ausencia de una regulación uniforme que concentre todas y cada una de las materias objeto de consulta, ya que la legislación especial que las regula es ambigua y genérica en lo que al tratamiento de tema de trascendencia nacional se refiere. De hecho, se 


\section{Revista Iberoamericana \\ de las Ciencias Sociales y Humanísticas}

ISSN: $2395-7972$

limita a establecer únicamente los tópicos que escapan de su aplicación, permitiendo con ello un margen bastante amplio de discrecionalidad tanto en la amplitud de temáticas como en su desarrollo y ponderación de resultados, lo que favorece su manipulación por el ente convocante y la determinación misma del carácter trascendente de un tópico objeto de consulta.

Por otra parte, se constató que el sistema jurídico mexicano no cuenta con una adecuada regulación normativa aplicable a tópicos propios de dichas consultas debido a las razones expuestas en las conclusiones previas.

Por tanto, se comprueba irrebatiblemente que, ante su ínfimo grado de eficacia y eficiencia, no es factible garantizarles un alentador porvenir.

\section{Futuras Líneas de Investigación}

Se han identificado vertientes que ameritan ser abordadas en estudios complementarios y ulteriores, en virtud de no haber sido previstos al momento en que se diseñaron las bases primigenias de esta investigación.

Un tópico potencialmente susceptible de analizar a profundidad mediante la articulación de una línea de investigación, es el relacionado con modelo de democracia justificativa a partir de las aportaciones efectuadas por autores como Lorenzo Peña (en su análisis conceptual sobre dictadura, democracia, y república o con relación a la democracia justificativa como un nuevo modelo de República) o Jessica Baños (conforme a su investigación sobre los debates actuales en torno a las teorías de la democracia) a fin de constatar sus bondades e inconvenientes frente al esquema tradicional de democracia electiva, pretendiendo corroborar la existencia de una verdadera complementariedad fincada en la proximidad entre el poder ejercido por los ciudadanos organizados y los sujetos con pretensiones de desplegar representatividad, y si con ella se lograría una auténtico incremento en la participación de voluntades decisorias fundada en una irrestricta responsabilidad.

Otro aspecto de suma relevancia, con prospección y factibilidad de ser inquirido en futura línea de investigación, es el vinculado con el diseño y aplicación de las consultas públicas, así como la metodología de interpretación, validación y ponderación de los resultados obtenidos a través de este mecanismo de expresión y participación democrática, lo que nos llevaría muy probablemente a la creación de un modelo universal de consulta 
Revista Iberoamericana

de las Ciencias Sociales y

Humanísticas

ISSN: 2395 - 7972

pública inspirándonos en ejemplos como el brindado por el Consejo de la Transparencia de Chile; por Flavia Milano y Andrea Sanhueza mediante su propuesta de Guías para Agencias Ejecutoras Públicas y Privadas de Consultas Públicas con Sociedad Civil, o por el Grupo del Banco Interamericano de Desarrollo que nos da a conocer el paso a paso de las consultas públicas a través de 300 marcos regulatorios y legales aplicables en América Latina y el Caribe.

\section{Referencias}

Alexy, R. (2012). La construcción de los derechos fundamentales. Buenos Aires. Argentina. Colección: Derecho, Estado y Sociedad.

Boutros-Ghali, B. (2003). La interacción entre democracia y desarrollo. Informe de síntesis. París: Organización de las Naciones Unidas (Unesco).

Bovero, M. (2012). ¿Elecciones sin democracia? ¿Democracia sin elecciones? Sobre las formas de participación política. Revista Justicia Electoral, 1(10), 317-351.

Calabresi, G. (1970). Yale University Press. Retrieved from https://www.jstor.org/stable/j.ctt1cc2mmw

Cámara de Diputados del H. Congreso de la Unión (14 de marzo de 2014). Ley Federal de Consulta Popular. Diario Oficial de la Federación del 14 de marzo de 2014. http://www.diputados.gob.mx/LeyesBiblio/index.htm

Capellán de Miguel, G. (2018). El concepto democracia: momentos, significados e imágenes en la "larga duración" (una propuesta para repensar la historia conceptual en el mundo iberoamericano). Ariadna histórica. Lenguajes, conceptos, metáforas, 7, 101146. Recuperado de http://www.ehu.es/ojs/index.php/Ariadna/index

Coase, R. (1960). The problem of social cost. The Journal of Law \& Economics, 3, 1-44. Retrieved from http://www.jstor.org/stable/724810

Congreso de la Ciudad de México. I Legislatura (2019, 12 de agosto, cuya última modificación fue efectuada el 29 de julio de 2020). Ley de Participación Ciudadana de la Ciudad de México. Gaceta Oficial de la Ciudad de México del 12 de agosto de 2019 y 29 de julio de 2020. Recuperado de https://www.congresocdmx.gob.mx/media/documentos/394fa901ac5d1dae074b248 48ab66998265eb2fa.pdf 
Revista Iberoamericana

de las Ciencias Sociales y

Humanísticas

ISSN: 2395 - 7972

Consejo Interparlamentario de la Unión Interparlamentaria (UIP) (1997). Résultats 98e Conférence et Réunions Connexes de l'Union Interparlementaire. Résultats Union Interparlementaire, Le Caire.

Constitución Política de los Estados Unidos Mexicanos (1917). Diario Oficial de la Federación del 5 de febrero de 1917 (última reforma publicada el 8 de mayo de 2020). Artículos principalmente materia de análisis: 35, fracción VII, y 36, fracción III, 40. Recuperado de http://www.diputados.gob.mx/LeyesBiblio/index.htm

Cooter, R. and Ulen, T. (2016). Law and Economics (6 ${ }^{\text {th }}$ ed., vol. I). (B. L. Repository, Ed.) Berkeley, California, USA: Berkeley Law Books. Retrieved from https://scholarship.law.berkeley.edu/cgi/viewcontent.cgi?article=1001\&context=boo ks

Cossío, J. R. (2015). Derecho y análisis económico (vol. I). México, México: Fondo de Cultura Económica.

Dewey, J. (1998). Demogracy and Education. An Introduction to the Philosophy of Education (6. ${ }^{\text {a }}$ reimpresión) (L. Luzuriaga, Trad.). Madrid, España: Ediciones Morata, S. L.

Escobar, L. (2014). La consulta popular en México. Revista de la Facultad de Derecho de México, 64(262). Doi: http://dx.doi.org/10.22201/fder.24488933e.2014.262.60351

Fernández, J. F. (2013). La democracia como forma de gobierno (7. a reimpresión). Ciudad de México, México: Instituto Federal Electoral. pp. 66-69. Recuperado de https://portalanterior.ine.mx/archivos3/portal/historico/recursos/IFEv2/DECEYEC/DECEYEC-CuadernosDivulgacion/2015/cuad_3.pdf

Ferrajoli, L. (2004). Derechos y garantías. La ley del más débil (prólogo de perfecto: Andrés Ibáñez. Traducción de Perfecto Andrés Ibáñez y Andrea Greppi). Collección Estructuras y Procesos. Serie Derecho. Editorial Trotta.

International Institute for Democracy and Electoral Assistance (IDEA) (2017). The Global State of Democracy. Exploring Democracy's Resilience. (K. Friel, Ed.) Stockholm, Sweden: International Institute for Democracy and Electoral Assistance (IDEA).

Konrad-Adenauer-Stiftung (KAS) (2011). Concepts and Principles of Democratic Governance and Accountability. Action for Strengthening Good Governance and Accountability in Uganda' by the Uganda Office of the Konrad-Adenauer-Stiftung. Kampala, Uganda: Konrad-Adenauer-Stiftung. 
Milano, A. y Zanhueza, A. (2016). Consultas públicas con sociedad civil: guías para agencias ejecutoras públicas y privadas. Banco Interamericano de Desarrollo.

Nogueira, H. (2003). Teoría y dogmática de los derechos fundamentales. México: Universidad Nacional Autónoma de México.

Oficina Internacional del Trabajo (OIT) (2016). Procedimientos para la celebración de consultas con los pueblos indígenas. Experiencia de Noruega. Ginebra, Suiza.

Organización de las Naciones Unidas (ONU) (1948). Resolución 217 A (III), relativa a la Declaración Universal de Derechos Humanos. Proclamada en París el 10 de diciembre de 1948 por la Asamblea General. Recuperado de https://www.un.org/es/universal-declaration-human-rights/

Organización de las Naciones Unidas (ONU) (2013-2019). UN Department of Political Affairs (DPA) in close partnership with the United Nations Development Programme $(U N D P)$. Retrieved from https://constitutionmaker.un.org/

Peña, L. (2009). Dictadura, democracia, república: un análisis conceptual. Memoria del Primer Encuentro Internacional sobre el poder en el pasado y el presente de América Latina. Toluca: Universidad Autónoma del Estado de México.

Rojas, R. (2012). Métodos para la investigación social. Una proposición dialéctica (18. ${ }^{\mathrm{a}}$ ed.). Madrid, España: Plaza y Valdés Editores.

Rojas, R. (2013). Guía para realizar investigaciones sociales (38. ${ }^{\mathrm{a}}$ ed.). México., México.: Plaza y Valdés, S.A. de C.V.

Sáenz, K. A. y Rodríguez, K. E. (2010). La promoción de la participación ciudadana. En Estrada Camargo, M. y Sáenz. K. (comps.), Elecciones, gobierno y gobernabilidad (pp. 149-176). México, México: Instituto Federal Electoral.

Sartori, G. (2009). La democracia en 30 lecciones (L. Foschini, Ed. y A. Pradera, Trad.). México, México: Santillana Ediciones Generales, S. A. de C. V.

Tilly, C. (2007). Democracy. New York, USA: Cambridge University Press. 